\title{
Article
}

\section{VIDE: The Void IDentification and Examination toolkit}

Thompson, Ben

Available at http://clok.uclan.ac.uk/11264/

Thompson, Ben (2015) VIDE: The Void IDentification and Examination toolkit. Astronomy and Computing, 9 . pp. 1-9.

It is advisable to refer to the publisher's version if you intend to cite from the work. http://dx.doi.org/10.1016/j.ascom.2014.10.002

For more information about UCLan's research in this area go to http://www.uclan.ac.uk/researchgroups/ and search for < name of research Group>.

For information about Research generally at UCLan please go to http://www.uclan.ac.uk/research/

All outputs in CLoK are protected by Intellectual Property Rights law, including Copyright law. Copyright, IPR and Moral Rights for the works on this site are retained by the individual authors and/or other copyright owners. Terms and conditions for use of this material are defined in the policies page.

\section{CLoK}

Central Lancashire online Knowledge www.clok.uclan.ac.uk

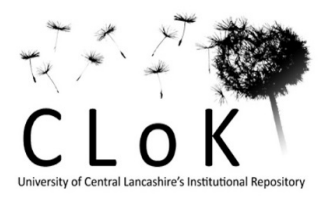




\section{SAO/ NASA ADS Astronomy Abstract Service}

- Find Similar Abstracts (with default settings below)

- Electronic On-line Article (HTML)

- arXiv e-print (arXiv: 1406.1191)

- References in the Article

- Citations to the Article (11) (Citation History)

- Refereed Citations to the Article

- Associated Articles

- Also-Read Articles (Reads History)

- Translate This Page

Title:

Authors:

Publication:

Publication Date:

Origin:

Bibliographic Code: 2014ascl.soft07014S

07/2014

ASCL
VIDE: The Void IDentification and Examination toolkit

Sutter, P. M.; Lavaux, Guilhem; Hamaus, Nico; Pisani, Alice; Wandelt, Benjamin D.; Warren, Michael S.; Villaescusa-Navarro, Francisco; Zivick, Paul; Mao, Qingqing; Thompson, Benjamin B.

Astrophysics Source Code Library, record ascl:1407.014

\section{Abstract}

The Void IDentification and Examination toolkit (VIDE) identifies voids using a modified version of the parameter-free void finder ZOBOV (ascl:1304.005); a Voronoi tessellation of the tracer particles is used to estimate the density field followed by a watershed algorithm to group Voronoi cells into zones and subsequently voids. Output is a summary of void properties in plain ASCII; a Python API is provided for analysis tasks, including loading and manipulating void catalogs and particle members, filtering, plotting, computing clustering statistics, stacking, comparing catalogs, and fitting density profiles.

\section{Associated Articles}

Paper 1 Source Software

Bibtex entry for this abstract Preferred format for this abstract (see Preferences)

Add this article to private library

Submit corrections to this record
Remove this article from private library

View record in ADSLabs NEW! 
$\begin{array}{ll}\text { Use: } & \text { Authors } \\ & \text { Title }\end{array}$

Abstract Text

Return: $\quad$ Query Results Return 100 items starting with number 1

Query Form

Database: Astronomy

Physics

arXiv e-prints 